\title{
Posterior Approach for Laparoscopic Pancreaticoduodenectomy to Prevent Replaced Hepatic Artery Injury
}

\author{
Satoshi Ogiso, $\mathrm{MD}^{1,2}$, Claudius Conrad, $\mathrm{MD}, \mathrm{PhD}^{1,3}$, Kenichiro Araki, MD, $\mathrm{PhD}^{\mathbf{1}}$, Valeria Basso, $\mathrm{MD}^{\mathbf{1}}$, \\ and Brice Gayet, $\mathrm{MD}, \mathrm{PhD}^{1}$
}

${ }^{1}$ Department of Digestive Pathology, Institute Mutualiste Montsouris, Paris Descartes University, Paris, France; ${ }^{2}$ Division of Hepato-Pancreato-Biliary and Transplant Surgery, Department of Surgery, Graduate School of Medicine, Kyoto University, Kyoto, Japan; ${ }^{3}$ Department of Surgery, Massachusetts General Hospital, Harvard Medical School, Boston, MA

\begin{abstract}
Background. Laparoscopic pancreaticoduodenectomy (PD) has become more popular despite its complexity and tendency for higher morbidity. ${ }^{1}$ Replaced right hepatic artery (RRHA) and replaced common hepatic artery (RCHA), both originating from the superior mesenteric artery (SMA), are the most significant and relatively common vascular anomalies in patients undergoing PD, occurring in 8.6-21 and $0.4-4.5 \%$ of cases, respectively. ${ }^{2,3}$ An inadvertent injury to theses arteries may result in an intra- or postoperative bleeding, hepatic or bile duct ischemia, and consequent leakage or delayed stricture in the bilioenteric anastomosis. ${ }^{2-4}$ Therefore, preservation of these aberrant hepatic arteries is essential unless their resection is oncologically indicated. ${ }^{2}$ We describe a posterior approach that can be advantageous in laparoscopic PD for patients with a RRHA or RCHA.

Methods. The posterior approach was used in 81 laparoscopic PDs at the Institute Mutualiste Montsouris between 1994 and 2012. ${ }^{5}$ In brief, retropancreatic dissection is performed to complete kocherization and expose the posterolateral aspect of the SMA. The origin of the RRHA or RCHA can then be identified and dissected. After division of the pancreatic neck, the portal vein and RRHA or RCHA are separated off the pancreatic neck. In case of the RCHA,
\end{abstract}

Electronic supplementary material The online version of this article (doi:10.1245/s10434-013-3058-7) contains supplementary material, which is available to authorized users.

(C) Society of Surgical Oncology 2013

First Received: 15 April 2013;

Published Online: 21 June 2013

B. Gayet, $\mathrm{MD}, \mathrm{PhD}$

e-mail: brice.gayet@imm.fr the gastroduodenal artery originating from the RCHA is divided during this dissection.

Results. The video shows a secure procedure to preserve a RCHA in laparoscopic PD by early identification and dissection of the aberrant artery via the posterior approach.

Conclusions. The posterior approach can help to prevent inadvertent RRHA or RCHA injury in laparoscopic PD.

DISCLOSURE The authors declare no conflict of interest.

\section{REFERENCES}

1. Fisher SB, Kooby DA. Laparoscopic pancreatectomy for malignancy. J Surg Oncol. 2013;107:39-50.

2. Shukla PJ, Barreto SG, Kulkarni A, et al. Vascular anomalies encountered during pancreatoduodenectomy: do they influence outcomes? Ann Surg Oncol. 2010;17:186-93.

3. Chamberlain RS, El-Sedfy A, Rajkumar D. Aberrant hepatic arterial anatomy and the Whipple procedure: lessons learned. Am Surg. 2011;77:517-26.

4. Traverso LW, Freeny PC. Pancreaticoduodenectomy. The importance of preserving hepatic blood flow to prevent biliary fistula. Am Surg. 1989;55:421-6.

5. Gumbs AA, Gayet B. The laparoscopic duodenopancreatectomy: the posterior approach. Surg Endosc. 2008;22:539-40. 